\title{
Effect of Gamma-Irradiated Recycled Low-Density Polyethylene on the High- and Low-Temperature Properties of Bitumen
}

\author{
Perviz Ahmedzade, ${ }^{1}$ Alexander Fainleib, ${ }^{2}$ Taylan Günay, ${ }^{3}$ \\ Olga Starostenko, ${ }^{2}$ and Tetyana Kovalinska ${ }^{4}$ \\ ${ }^{1}$ Transportation Division, Department of Civil Engineering, Faculty of Engineering, Ege University, Izmir, Turkey \\ ${ }^{2}$ Institute of Macromolecular Chemistry of the National Academy of Sciences of Ukraine (NASU), Kyiv, Ukraine \\ ${ }^{3}$ Department of Civil Engineering, Ege University, Izmir, Turkey \\ ${ }^{4}$ Institute of Nuclear Research of the NASU, Kyiv, Ukraine
}

Correspondence should be addressed to Perviz Ahmedzade; perviz.ahmedzade@ege.edu.tr

Received 29 March 2013; Accepted 3 June 2013

Academic Editor: Gonzalo Martínez-Barrera

Copyright (C) 2013 Perviz Ahmedzade et al. This is an open access article distributed under the Creative Commons Attribution License, which permits unrestricted use, distribution, and reproduction in any medium, provided the original work is properly cited.

\begin{abstract}
This paper describes polymer modification of bitumen with gamma-irradiated recycled $\left(\gamma\right.$-LDPE $\left.E_{R}\right)$ low-density polyethylene. The recycled low-density polyethylene $\left(\mathrm{LDPE}_{\mathrm{R}}\right)$ was obtained from greenhouse films exposed to sunlight at least one year. The surface of the $\mathrm{LDPE}_{\mathrm{R}}$ was treated by gamma beam irradiation that provided formation of free radicals and some functional groups that may contribute to the creation of strong chemical bonds between polymer modifier and bitumen. Five different samples of bitumen $/ \gamma$ $\mathrm{LDPE}_{\mathrm{R}}$ compositions with the modifier content, wt. \%: 1, 3, 5, 7 and 9, were prepared. The effects of the $\gamma$-LDPE $\mathrm{R}_{\mathrm{R}}$ on original and aged bitumen were investigated by means of morphological, chemical, and physical testing program, including FTIR spectroscopy, conventional tests, rotational viscosity (RV), dynamic shear rheometer (DSR), and bending beam rheometer (BBR) tests. Superior performing asphalt pavements (Superpave) specifications were used to analyze mechanical test results as well as to determine the performance grades (PG) of the binders. Optimum usage of the $\gamma-\mathrm{LDPE}_{\mathrm{R}}$ as modifier in bitumen were suggested after testing program. The results reveal the stiffening effect of the $\gamma-\mathrm{LDPE}_{\mathrm{R}}$ on bitumen that provide enhanced temperature susceptibility and also promise better performance grades (PG) with $\gamma$-LDPE $E_{R}$ polymer modification.
\end{abstract}

\section{Introduction}

The modification of bitumen by means of polymers is the most widespread method in flexible pavement applications. The polymers such as Styrene Butadiene Styrene (SBS), Ethylene vinyl acetate (EVA) are satisfactorily used to enhance temperature susceptibility by increasing stiffness at high temperature and decreasing stiffness at low temperature [14]. In addition to SBS, various polymers are utilized in bituminous materials. Polyolefins such as low-density polyethylene (LDPE), high density polyethylene (HDPE), and polypropylene (PP) have been used as modifier, for generally to enhance mechanical properties of bitumen [5-8].

On the other hand, using recycled polymers contributes to reducing amount of waste materials; it has many benefits, such as environmental protection, lower energy consumption, and their affordable cost. Therefore, it is fundamental to find an application area for recycled polymers, in order to increase their commercial use [9-11].

The aim of this work is to study the effect of recycled $\mathrm{LDPE}\left(\mathrm{LDPE}_{\mathrm{R}}\right)$ as modifier on bitumen by means of morphologic, chemical, and mechanical test methods. However, there is no chemical reaction between $\mathrm{LDPE}_{\mathrm{R}}$ and bitumen which results in a two-phase mixture after the preparation of modified bitumen. In order to provide strong polymer/bitumen bonding, surface of the recycled LDPE was activated by using gamma beam irradiation. The surface activation helps to create double bonds $(>\mathrm{C}=\mathrm{C}<$ ) that can interact with bitumen.

The study contains a comprehensive laboratory evaluation of the $\gamma$-irradiated recycled LDPE $\left(\gamma\right.$-LDPE $\left.\mathrm{R}_{\mathrm{R}}\right)$ modified bitumen $\left(\gamma-\mathrm{LDPE}_{\mathrm{R}} / \mathrm{B}\right)$ in terms of morphology and physicalchemical properties. Fluorescence microscopy has been used 
TABLE 1: Physical properties of the base bitumen.

\begin{tabular}{lcc}
\hline Properties & Standard & $160 / 220$ \\
\hline Penetration $\left(25^{\circ} \mathrm{C} ; 0.1 \mathrm{~mm}\right)$ & ASTM D5 & 195.5 \\
Softening point $\left({ }^{\circ} \mathrm{C}\right)$ & ASTM D36 & 38.7 \\
Ductility $\left(25^{\circ} \mathrm{C} ; \mathrm{cm}\right)$ & ASTM D113 & 103 \\
Penetration index $(\mathrm{PI})$ & - & -0.73 \\
Specific gravity $\left(25^{\circ} \mathrm{C} ; \mathrm{gr} / \mathrm{cm}^{3}\right)$ & ASTM D70 & 1.03 \\
\hline
\end{tabular}

to observe morphological changes, while rheological testing have been undertaken by means of dynamic shear rheometer (DSR) and bending beam rheometer (BBR). To understand the influence of $\gamma$-irradiation on structure and efficiency of the $\mathrm{LDPE}_{\mathrm{R}}$ recycled LDPE, Fourier transform infrared (FTIR) spectroscopy has been performed as well.

\section{Experimental}

2.1. Materials. The binders were prepared with the type of bitumen having 160/220 penetration grade. Physical properties of the bitumen are given in Table 1 . The $\mathrm{LDPE}_{\mathrm{R}}$ used as modifier in bitumen was supplied from Sicily, Italy. The $L_{D P E}$ was obtained from greenhouse films exposed to sunlight, as well as to other external environmental factors for one year. The waste films were washed, dried, cut into the pieces of dimensions $12 \times 12 \mathrm{~mm}$, and finally extruded. The chemical composition of the $\mathrm{LDPE}_{\mathrm{R}}$ used was LDPE 65$70 \%$, LLDPE $12-17 \%$, EVA copolymer $12-15 \%, T_{\mathrm{m}}=109^{\circ} \mathrm{C}$, $E=180 \mathrm{MPa}, \mathrm{TS}=16 \mathrm{MPa}, \mathrm{EB}=500 \%$, MFI190/2.16 = $0,29 \mathrm{~g} / 10 \mathrm{~min}$, and MFI230/2.16 $=0,95 \mathrm{~g} / 10 \mathrm{~min}$.

2.2. Gamma Irradiation Activation Method. In order to provide a chemical bonding between bitumen and polymer modifier, gamma irradiation method was applied to the $\mathrm{LDPE}_{R}$ [12]. Gamma irradiation method is used in several applications such as food processing, cancer treatments, and some sterilization systems. Gamma irradiation is electromagnetic of high frequency and rays are ionizing radiation. It provides a reformed chemical composition of the materials exposed to decay that might contribute to creating strong bonds between polymer modifier and bitumen. The irradiation source was an electron accelerator-complex electric device, where the transition from regimes of treatment with charged particles (electrons) to regimes of treatment with stream of gamma quanta of a wide range of energies is possible. The $\mathrm{LDPE}_{\mathrm{R}}$ granules were $\gamma$ irradiated with a dose of $20 \mathrm{kGy}$.

2.3. Preparation of Samples. $\gamma$-LDPE $\mathrm{R}_{\mathrm{R}}$ granules were obtained as pellet shaped. In order to work with smaller pieces, they were milled by using grinder and the particles were sieved with No 50. The amount of additives was selected as $\%: 1,3,5,7$, and 9 by total weight of the binder which is enough to examine the effect of the polymer modified bitumen. High shear mixer was employed for preparing sample. 160/220 penetration grade bitumen was heated for 90 minutes at $163^{\circ} \mathrm{C}$ and then poured into the mixer flask adjusted to $500 \mathrm{rpm}$. Subsequently, the $\gamma-\mathrm{LDPE}_{\mathrm{R}}$ was added to bitumen by portions in 15 minutes at certain intervals and then the mixing rate was increased to $1300 \mathrm{rpm}$ and mixing was continued for 150 minutes. After the end of the mixing process, the samples were removed from the flask, divided into small containers, covered with aluminum foil, and stored for various testing.

The different binders were coded as follows:

(i) base bitumen-"B;"

(ii) base bitumen $+1 \% \gamma-\mathrm{LDPE}_{\mathrm{R}}-$ "B-1- $\gamma$ - $\mathrm{LDPE}_{\mathrm{R}}$;"

(iii) base bitumen $+3 \% \gamma-\mathrm{LDPE}_{\mathrm{R}}-$ "B-3- $\gamma$ - $\mathrm{LDPE}_{\mathrm{R}}$;"

(iv) base bitumen $+5 \% \gamma-\mathrm{LDPE}_{\mathrm{R}}-$ "B-5- $\gamma$ - $\mathrm{LDPE}_{\mathrm{R}}$;"

(v) base bitumen $+7 \% \gamma$ - $\mathrm{LDPE}_{\mathrm{R}}-$ "B-7- $\gamma$-LDPE $\mathrm{R}_{\mathrm{R}}$;"

(vi) base bitumen $+9 \% \gamma-\mathrm{LDPE}_{\mathrm{R}}-$ "B-9- $\gamma$ - $\mathrm{LDPE}_{\mathrm{R}}$;"

\subsection{Testing Program}

2.4.1. Fourier Transform Infrared Spectroscopy. Fourier transform infrared (FTIR) spectroscopy was used to characterize various functional groups in asphalt and polymer modifier. FTIR spectra were recorded with a Bruker Tensor 27 DTGS spectrometer between 4000 and $450 \mathrm{~cm}^{-1}$ using the attenuated total reflection (ATR) mode. For each spectrum, 32 consecutive scans with a resolution of $4 \mathrm{~cm}^{-1}$ were averaged.

2.4.2. Morphology. In order to determine the grade of the dispersion of the modifier within the bitumen, fluorescent microscopy was used. Florescent microscopy allows researchers to study the morphology of bitumen by using a principle in which polymers become swollen after absorbing some of the constituents of the original bitumen [13].

The method of sample preparation for fluorescent microscopy followed the regular procedure that is consisted of heating, homogenizing, and cooling process. The samples were examined under a Carl Zeiss Primo Star generated from a $40 \mathrm{~W}$ halogen lamp and magnify up to $1000 \mathrm{X}$.

2.4.3. Conventional Bitumen Tests. The samples of the base and modified bitumen were subjected to conventional tests that are, namely, penetration (ASTM D5), softening point (ASTM D36), and ductility (ASTM D 113). By using penetration and softening point values, penetration index was calculated for each sample of bitumen to investigate the temperature susceptibility of bitumen. A classical approach related to PI calculation has been given in the Shell Bitumen Handbook [14] as shown in the following equation:

$$
\mathrm{PI}=\frac{1952-500 \times \log \left(\mathrm{Pen}_{25}\right)-20 \times \mathrm{SP}}{50 \times \log \left(\mathrm{Pen}_{25}\right)-\mathrm{SP}-120},
$$

where $\mathrm{Pen}_{25}$ is the penetration at $25^{\circ} \mathrm{C}$ and $\mathrm{SP}$ is the softening point temperature of the unmodified and modified bitumen.

2.4.4. Rotational Viscosity Test. The rotational viscometer determines the bitumen viscosity by measuring the torque necessary to maintain a constant rotational speed of a cylindrical spindle submerged in a bitumen specimen held 
at a constant temperature, described in AASHTO TP48. Unlike the capillary viscometers used with the viscositygraded method, the rotational viscometer can evaluate modified bitumen binders. Viscosity of bitumen binders can be measured within the range from $0.01 \mathrm{~Pa} \cdot \mathrm{s}$ ( 0.1 poise) to $200 \mathrm{~Pa} \cdot \mathrm{s}$ (2000 poise) [15]. Though this test, which is one of the Superpave Performance Grade (PG) asphalt binder specification, can be conducted at various temperatures for different purposes, the test performed for Superpave PG asphalt binder specification is always conducted at $275^{\circ} \mathrm{F}$ $\left(135^{\circ} \mathrm{C}\right)$. In order to observe the changes in viscosity at various temperatures, a second viscosity reading is taken generally at $165^{\circ} \mathrm{C}$. A Brookfield viscometer (DVRV-II Pro Extra) was used in this study for the viscosity tests of the base and the modified bitumens. Viscosity values were measured at $135^{\circ} \mathrm{C}$ and $165^{\circ} \mathrm{C}$, respectively.

2.4.5. Dynamic Shear Rheometer Test. The most commonly used methods for the fundamental rheological characterization of bitumen are dynamic mechanical methods using oscillatory type testing, generally conducted within the region of linear viscoelastic response by using a dynamic shear rheometer (DSR). In order to characterize the viscoelastic behavior of bitumen binders at intermediate and high service temperatures, DSR is used in Superpave specification providing an indication of the rutting resistance of bitumen immediately following the construction. It is also possible to evaluate the resistance to rutting at high service temperatures in the early stages of pavement life and fatigue cracking at immediate service temperatures in the later stages of service life by DSR [16].

The principal viscoelastic parameters obtained from DSR are the complex shear modulus $\left(\mathrm{G}^{*}\right)$ and the phase angle $(\delta) . G^{*}$ is defined as the ratio of maximum (shear) stress to maximum strain, a measure of the total resistance to deformation when the bitumen is subjected to shear loading. The phase difference between stress and strain in an oscillatory test is named as $\delta$, a measure of the viscoelastic balance of the material behavior [17].

In this study, the principal viscoelastic parameters such as $\mathrm{G}^{*}, \delta$, rutting parameter $\left(\mathrm{G}^{*} / \sin \delta\right)$, and high-temperature performance grades of the base and modified bitumens were determined by DSR test.

2.4.6. Bending Beam Rheometer Test. The bitumen binder plays a critical role in the thermal cracking potential of hot mix asphalt (HMA) pavement. HMA pavements with a high stiffness modulus at low temperatures are susceptible to thermal cracking. Bitumen binders become harder, or stiffer, as the ambient temperature decreases. Given that the stiffness of an HMA pavement is directly proportional to the stiffness of bitumen binder, high stiffness at low temperatures increases the potential of thermal cracking. The bending beam rheometer (BBR) was developed to determine the stiffness of bitumen binders at low service temperatures and to evaluate the potential of the binder for thermal cracking [16].

Creep tests were conducted at $-6,-12$, and $-18^{\circ} \mathrm{C}$ which are equivalent to $-16,-22$, and $-28^{\circ} \mathrm{C}$, respectively, in low

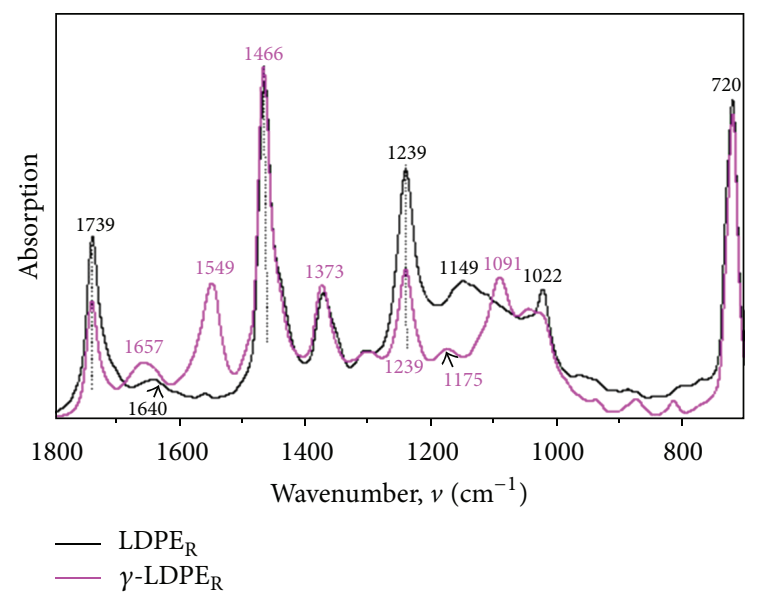

FIGURE 1: The normalized FTIR spectra of the $\mathrm{LDPE}_{\mathrm{R}}$ and $\gamma$-LDPE $\mathrm{R}_{\mathrm{R}}$.

temperature performance grade, using a BBR according to ASTM D6648-01. The bitumen beam (125 mm long, $12.5 \mathrm{~mm}$ wide, and $6.25 \mathrm{~mm}$ thick) was submerged in a constanttemperature bath and kept at the test temperature for $60 \mathrm{~min}$. After preloading procedure, a constant load of $100 \mathrm{~g}(980 \mathrm{mN})$ was then applied to the rectangular beam supported at both ends by stainless steel half-rounds ( $102 \mathrm{~mm}$ apart), and the deflection of center point was measured continuously. Creep stiffness $(S)$ and creep rate ( $m$-value) of the binders were determined at several durations of loading ranging from 8 to $240 \mathrm{~s}$ [18]. The creep stiffness is an indicator of the specimen's ability to resist the constant creep load and the creep rate is the rate at which the creep stiffness changes with loading time [16]. For an adequate low-temperature cracking resistance, the creep stiffness must be less than $300 \mathrm{MPa}$ and the $m$-value must be greater than 0.3 to be in compliance with Superpave specification [19].

\section{Results and Discussions}

3.1. FTIR Spectroscopy. In Figure 1, the normalized FTIR spectra (the band at $v \approx 720 \mathrm{~cm}^{-1}$ has been used as internal standard) of the virgin $\mathrm{LDPE}_{\mathrm{R}}$ and $\gamma-\mathrm{LDPE}_{\mathrm{R}}$ are shown. As can be seen from Figure 1, there is no significant difference in position and intensity of the main absorption bands at $\nu \approx$ $720,1022,1373$, and $1466 \mathrm{~cm}^{-1}$, which are the characteristics for vibrations of $\mathrm{C}-\mathrm{C}$ and $\mathrm{C}-\mathrm{H}$ bonds of hydrocarbon chain of virgin $\mathrm{LDPE}$ and $\gamma-\mathrm{LDPE}_{\mathrm{R}}$. However, the new peaks are additionally observed at $v \approx 1091,1175,1549$, and $1657 \mathrm{~cm}^{-1}$ in the spectrum of $\gamma-\mathrm{LDPE}_{\mathrm{R}}$ accompanied by decreasing intensity of the peaks at $1239 \mathrm{~cm}^{-1}$ and $1739 \mathrm{~cm}^{-1}$. These new peaks evidence formation of unsaturated bonds in macromolecular chains of gamma-irradiated LDPE (the peak with maximum at $v \approx 1657 \mathrm{~cm}^{-1}$ corresponds to the nonconjugated $\mathrm{C}=\mathrm{C}$ bond) that is occurred as a result of highenergy action of the gamma-rays on LDPE. At irradiation treatment free radicals appear at breakage of polymer chains, which can then transform to different groups and bonds including formation of double bonds $(>\mathrm{C}=\mathrm{C}<)$. Certainly, 

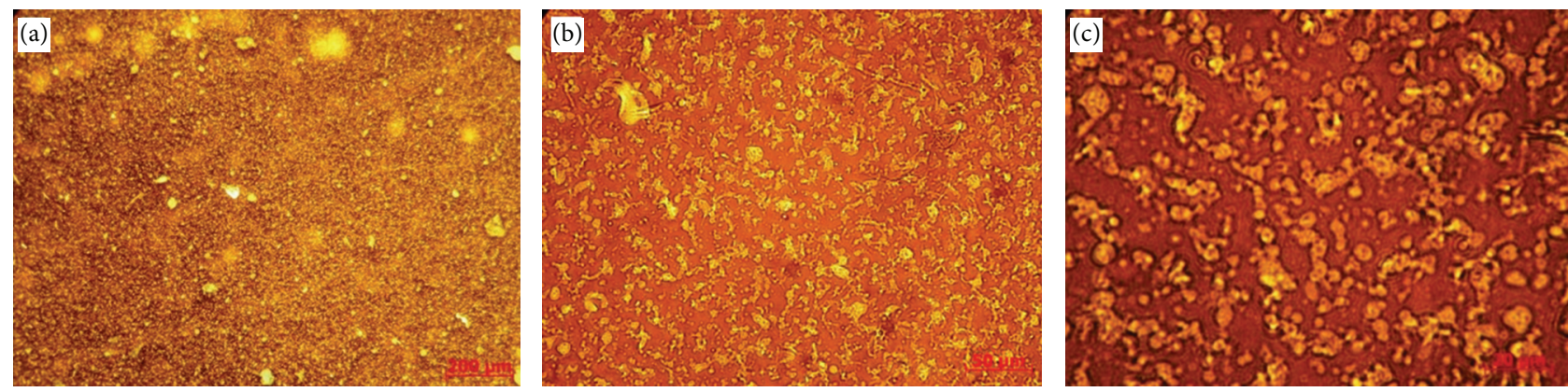

FIgURE 2: (a) 50X magnification, (b) 200X magnification, and (c) 500X magnification.

TABLE 2: Characteristic properties of base and $\gamma$-LDPE $E_{R}$ modified bitumens before and after short-term ageing.

\begin{tabular}{|c|c|c|c|c|c|c|}
\hline \multirow{3}{*}{ Properties } & \multicolumn{6}{|c|}{ Binder types } \\
\hline & \multicolumn{6}{|c|}{ Modified Bitumens } \\
\hline & Base & $1-\gamma-\mathrm{LDPE}_{\mathrm{R}}$ & $3-\gamma-\mathrm{LDPE}_{\mathrm{R}}$ & $5-\gamma-\mathrm{LDPE}_{\mathrm{R}}$ & $7-\gamma-\mathrm{LDPE}_{\mathrm{R}}$ & 9- $\gamma-\mathrm{LDPE}_{\mathrm{R}}$ \\
\hline Penetration $\left(25^{\circ} \mathrm{C} ; 0.1 \mathrm{~mm}\right)$ & 195.5 & 168.8 & 135 & 102 & 83.1 & 57.2 \\
\hline Softening point $\left({ }^{\circ} \mathrm{C}\right)$ & 38.7 & 42.5 & 48.4 & 64.2 & 60.3 & 70.5 \\
\hline Ductility $(\mathrm{cm})$ at $25^{\circ} \mathrm{C}$ & 103 & 92 & 84 & 77 & 69 & 63 \\
\hline Penetration index (PI) & -0.73 & 0.23 & 1.31 & 1.85 & 2.54 & 3.28 \\
\hline \multicolumn{7}{|c|}{ After ageing } \\
\hline Change of mass (\%) & 0.76 & 0.68 & 0.65 & 0.40 & 0.37 & 0.35 \\
\hline Penetration $\left(25^{\circ} \mathrm{C} ; 0.1 \mathrm{~mm}\right)$ & 102 & 85.6 & 125 & 93.8 & 76.5 & 52.5 \\
\hline Retained penetration (\%) & 52 & 50.7 & 92.5 & 91.9 & 92 & 92 \\
\hline Softening point $\left({ }^{\circ} \mathrm{C}\right)$ & 42.7 & 45.3 & 49.5 & 65.1 & 61.1 & 66.5 \\
\hline Change in softening point $\left({ }^{\circ} \mathrm{C}\right)$ & 4 & 2.8 & 1.1 & 0.9 & 0.8 & -4 \\
\hline
\end{tabular}

the unsaturated bonds formed in $\gamma$-LDPE $\mathrm{R}_{\mathrm{R}}$ are reactive towards the unsaturated bonds of bitumen components that provides effective reactive compatibilization of the blends of modifier with bitumen through the chemical reactions of the surface functional groups of the activated polyethylene and the double bonds of the bitumen components. In air, the free radicals formed can react with oxygen forming some oxygencontaining functional groups in polymer structure (e.g., $\mathrm{C}(\mathrm{O}) \mathrm{O}$ - group of organic acids or esters with a maximum around $\nu \approx 1549 \mathrm{~cm}^{-1}$ and $-\mathrm{C}-\mathrm{O}-\mathrm{C}-$ bond in ethers with an absorption bands around $\nu \approx 1091,1175)$. These groups can also contribute to physical-chemical compatibilization of $\gamma$-LDPE $\mathrm{R}_{\mathrm{R}}$ with bitumen.

3.2. Morphology. The morphology of $\gamma-\mathrm{LDPE}_{\mathrm{R}}$ modified bitumen was observed with a fluorescent microscope The images given in Figure 2 belong to B-9- $\gamma-L_{D P E}$, the highest polymer content among the all binders. The surface images were taken with using different magnification (i.e. 50X, 200X and 500X). Figure 2(a) shows the texture of the modified bitumen in general, whereas Figure 2(c) shows a detailed image on texture and allows observing the phase structure of the modified bitumen. Two major phases that can be clearly seen (Figures 2(a), 2(b), and 2(c)) are a continuous bitumenrich phase (brown) and a dispersed polymer phase (yellow). Excluding a few greater particles, the main amount of $\gamma$ $\mathrm{LDPE}_{\mathrm{R}}$ is mostly ranging from 3 to $10 \mu \mathrm{m}$ in diameter and is quite well dispersed in bitumen. While modifier particles with a size greater than $30 \mu \mathrm{m}$ were not seen generally in the modified bitumen samples, it can be said that polymer particles have been swollen by absorbing an amount of the bitumen content. A third phase (mixed phase) can be observed in the image taken at the $500 \mathrm{X}$ magnification (Figure 2(c)) formed in interface region obviously due to chemical bonding between bitumen and gamma-irradiated polymer particles.

3.3. Conventional Bitumen Test. In order to understand the effect of $\gamma$-LDPE $E_{\mathrm{R}}$ additives on physical properties of the bitumen, conventional tests were conducted. The results, including both before and after short-term ageing, are given in Table 2. As can be seen, penetration decreases continuously with increasing amount of $\gamma-\mathrm{LDPE}_{\mathrm{R}}$ polymer content.

Hence, B-9- $\gamma-\mathrm{LDPE}_{\mathrm{R}}$ binder has the lowest penetration value with 57.2. Softening point test results support penetration results, as it increases with increasing $\gamma-\mathrm{LDPE}_{\mathrm{R}}$ polymer content. These physical tests results point out a significant increase in stiffness of the bitumen with increasing amount of the polymer modifier. There is no specification limits for ductility, it is generally expected to be higher than $100 \mathrm{~cm}$. Consequently, decreasing ductility means, binders become more brittle with increasing amount of $\gamma$-LDPE $E_{R}$ modifier.

The PI values increase progressively from -0.73 to 3.28 , as modifier content increases that signifies $\gamma-\mathrm{LDPE}_{\mathrm{R}}$ polymer 
TABLE 3: Viscosity values of the of base and $\gamma$-LDPE $E_{R}$ modified bitumens.

\begin{tabular}{lcccccc}
\hline \multirow{2}{*}{ Binder types } & \multicolumn{2}{c}{ Rotational viscosity $(\mathrm{cP})$} & \multicolumn{2}{c}{$\eta_{\text {modified }} / \eta_{\text {pure }}$} & \multicolumn{2}{c}{ Temperature range $\left({ }^{\circ} \mathrm{C}\right)$} \\
& $135^{\circ} \mathrm{C}$ & $165^{\circ} \mathrm{C}$ & $135^{\circ} \mathrm{C}$ & $165^{\circ} \mathrm{C}$ & Mixing & Compaction \\
\hline $\mathrm{B}$ & 202.5 & 65.5 & 1 & 1 & $135-142$ & $122-128$ \\
$\mathrm{~B}-1-\gamma-\mathrm{LDPE}_{\mathrm{R}}$ & 250 & 80 & 1.23 & 1.22 & $142-148$ & $129-135$ \\
$\mathrm{~B}-3-\gamma-\mathrm{LDPE}_{\mathrm{R}}$ & 380 & 122.5 & 1.88 & 1.87 & $152-159$ & $139-145$ \\
$\mathrm{~B}-5-\gamma-\mathrm{LDPE}_{\mathrm{R}}$ & 702.5 & 208 & 3.47 & 3.18 & $165-171$ & $154-159$ \\
$\mathrm{~B}-7-\gamma-\mathrm{LDPE}_{\mathrm{R}}$ & 798 & 330 & 3.94 & 5.04 & $187-195$ & $170-177$ \\
$\mathrm{~B}-9-\gamma$ LDPE $_{\mathrm{R}}$ & 1286 & 435 & 6.35 & 6.64 & $189-195$ & $175-181$ \\
\hline
\end{tabular}

modified bitumen can be used in a wider temperature range than base bitumen.

The tests performed on aged samples reveal that $\gamma$ $L_{D P E}$ additives have a positive effect on ageing properties of bitumen, as mass loss of the bitumen diminishes. Furthermore, the results of all the samples are within the limitation of change of mass (i.e., 1\%). After short-term ageing, the retained penetration tends to increase as $\gamma$-LDPE $E_{R}$ content increases which shows that increasing polymer content helps to diminish the effects of ageing on bitumen binders.

3.4. Rotational Viscosity Results. Rotational viscosities performed at 135 and $165^{\circ} \mathrm{C}$ for base and $\gamma$-LDPE $E_{\mathrm{R}}$ modified bitumens are shown in Table 3. For all the samples, mixing and compaction temperatures were determined from the viscosity versus temperature graph given in Figure 3 . The results reveal a gradual increase in viscosity with modification. As in the penetration and softening point test, this increasing in viscosity gives a clear indication of the stiffening effect of $\gamma-\mathrm{LDPE}_{\mathrm{R}}$ modification. Modification indices, which can be calculated as the viscosity of modified bitumen divided by the viscosity of base bitumen, especially have greater values for B-5- $\gamma-\mathrm{LDPE}_{R}, \mathrm{~B}-7-\gamma-\mathrm{LDPE}_{R}$, and B-9- $\gamma-\mathrm{LDPE}_{R}$ binders. Calculated mixing and compaction temperatures for the base and modified binders tend to increase continuously. Although there are no viscosity values exceeding the Superpave specifications (i.e., $3000 \mathrm{cP}$ ) for both base and modified bitumen, this increase in mixing and compaction temperatures means that the workability of bitumen considerably decreases. Besides, mixing temperature of $\mathrm{B}$ $7-\gamma-\mathrm{LDPE}_{\mathrm{R}}$ and $\mathrm{B}-9-\gamma-\mathrm{LDPE}_{\mathrm{R}}$ binders reaches $195^{\circ} \mathrm{C}$, which can be considered as unfavorable result, because it means that the energy consumption will increase to high levels in applications.

3.5. Dynamic Shear Rheometer Test. In this study, hightemperature performances grades of base and modified bitumens were investigated by means of DSR tests. The fundamental rheological parameters for bitumen such as $\mathrm{G}^{*}, \delta$, and $\mathrm{G}^{*} / \sin \delta$ were also determined for original and aged samples in this DSR testing program, and the results are given in Table 4 and Figure 4 . Table 4 also contains the high-temperature performance grades (PG) calculated with minimum rutting parameter $\left(\mathrm{G}^{*} / \sin \delta\right)$ criteria of $1 \mathrm{kPa}$ for original samples and $2.2 \mathrm{kPa}$ for aged samples recommended in Superpave binder specifications. As can be seen, the

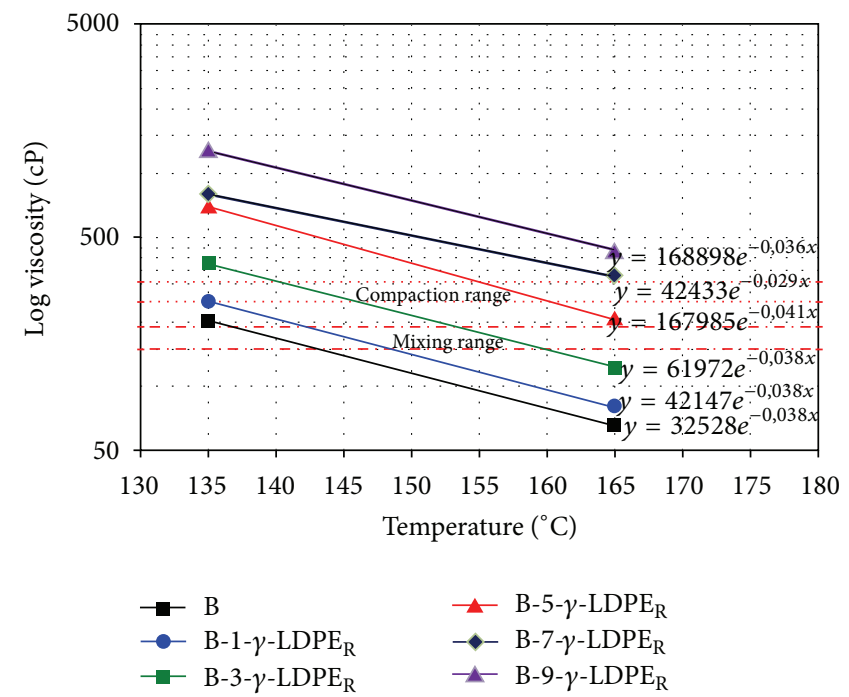

FIGURE 3: The mixing-compaction temperatures for the base and $\gamma$ $\mathrm{LDPE}_{\mathrm{R}}$ modified bitumens.

values of $G^{*}$, the measure of the total resistance of bitumen against the deformation subjected to the shear stress, increase significantly for both original and aged samples with increasing $\gamma$-LDPE $E_{R}$ modifier content. This result determines that binders become hardened after $\gamma$-LDPE $\mathrm{R}_{\mathrm{R}}$ modification. Therefore, it can be said that the $\gamma$-LDPE $E_{R}$ modified binders are more durable than original binders against shear stress deformations.

The phase angle $(\delta)$ is generally considered to be more sensitive to the chemical structure than the complex modulus, $\delta$ generally tends to decrease as the amount of modifier increases, and, therefore, predominantly viscous behavior with increasing temperatures, $\gamma-\mathrm{LDPE}_{\mathrm{R}}$ modifier improves the elastic response of the modified binders.

The effect of $\gamma$-LDPE $\mathrm{R}_{\mathrm{R}}$ modification on the rheological parameters $\left(\mathrm{G}^{*}\right.$ and $\delta$ ) leads to an increased rutting parameter $\left(\mathrm{G}^{*} / \sin \delta\right)$ of binders that promises an improvement of the rutting deformation. As values of $\mathrm{G}^{*} / \sin \delta$ within the limitations, DSR test is maintained to the next test temperatures.

The increased $\mathrm{G}^{*} / \sin \delta$ parameters also affect the PG of the binders. There is a significant increase in $P G$ with increase of $\gamma$-LDPE $\mathrm{R}_{\mathrm{R}}$ modifier, especially content of 5,7 , and $9 \%$. For instance, high-temperature performance grades step up to 
TABLE 4: DSR test results of the original and aged of base and $\gamma$-LDPE $E_{R}$ modified bitumens.

\begin{tabular}{|c|c|c|c|c|c|c|c|}
\hline Binder & & Temperature $\left({ }^{\circ} \mathrm{C}\right)$ & $\mathrm{G}^{*}(\mathrm{KPa})$ & $\delta\left(^{\circ}\right)$ & $\mathrm{G}^{*} / \sin \delta(\mathrm{KPa})$ & Specification limits $(\mathrm{Pa})$ & Performance grading \\
\hline \multirow{5}{*}{ B } & \multirow{3}{*}{ Original } & 52 & 4.64 & 86.6 & 4.65 & \multirow{3}{*}{$\geq 1000$} & \multirow{5}{*}{ PG 52-Y } \\
\hline & & 58 & 1.85 & 87.4 & 1.85 & & \\
\hline & & 64 & 0.766 & 88.2 & 0.767 & & \\
\hline & \multirow{2}{*}{ Aged } & 52 & 3.06 & 87.1 & 3.07 & \multirow{2}{*}{$\geq 2200$} & \\
\hline & & 58 & 1.39 & 87.2 & 1.39 & & \\
\hline \multirow{6}{*}{ B-1- $\gamma-\mathrm{LDPE}_{\mathrm{R}}$} & \multirow{3}{*}{ Original } & 52 & 2.75 & 80.7 & 2.78 & \multirow{3}{*}{$\geq 1000$} & \multirow{6}{*}{ PG 58-Y } \\
\hline & & 58 & 1.31 & 77.3 & 1.35 & & \\
\hline & & 64 & 0.702 & 72.7 & 0.735 & & \\
\hline & \multirow{3}{*}{ Aged } & 52 & 9.47 & 82.3 & 9.56 & \multirow{3}{*}{$\geq 2200$} & \\
\hline & & 58 & 4.07 & 84 & 4.10 & & \\
\hline & & 64 & 1.88 & 84.9 & 1.89 & & \\
\hline \multirow{7}{*}{ B-3- $\gamma-\mathrm{LDPE}_{\mathrm{R}}$} & \multirow{3}{*}{ Original } & 52 & 3.60 & 85.8 & 3.61 & \multirow{3}{*}{$\geq 1000$} & \multirow{7}{*}{ PG 58-Y } \\
\hline & & 58 & 1.66 & 85.5 & 1.66 & & \\
\hline & & 64 & 0.843 & 84.3 & 0.84 & & \\
\hline & \multirow{4}{*}{ Aged } & 52 & 10.6 & 78.7 & 10.6 & \multirow{4}{*}{$\geq 2200$} & \\
\hline & & 58 & 4.66 & 77.9 & 4.76 & & \\
\hline & & 64 & 2.42 & 74.7 & 2.42 & & \\
\hline & & 70 & 1.25 & 71.2 & 1.32 & & \\
\hline \multirow{8}{*}{ B-5- $\gamma-\mathrm{LDPE}_{\mathrm{R}}$} & \multirow{4}{*}{ Original } & 52 & 5.36 & 81.6 & 5.42 & \multirow{4}{*}{$\geq 1000$} & \multirow{8}{*}{ PG 64-Y } \\
\hline & & 58 & 2.47 & 79.9 & 2.51 & & \\
\hline & & 64 & 1.27 & 77.1 & 1.30 & & \\
\hline & & 70 & 0.72 & 73.4 & 0.75 & & \\
\hline & & 52 & 16.8 & 80 & 17.1 & & \\
\hline & Aged & 58 & 7.07 & 82.4 & 7.13 & $>2200$ & \\
\hline & & 64 & 3.14 & 83.7 & 3.16 & & \\
\hline & & 70 & 1.52 & 84.3 & 1.53 & & \\
\hline & & 52 & 7.69 & 84.5 & 7.72 & & \\
\hline & Original & 58 & 3.34 & 85.4 & 3.35 & $>1000$ & \\
\hline & & 64 & 1.62 & 85.4 & 1.63 & & \\
\hline $\mathrm{B}-7-\gamma-\mathrm{LDPE}_{\mathrm{R}}$ & & 70 & 0.863 & 84.1 & 0.868 & & PG 64-Y \\
\hline & & 52 & 20.7 & 77.7 & 21.2 & & \\
\hline & Aged & 58 & 9.04 & 80.2 & 9.18 & $\geq 2200$ & \\
\hline & & 64 & 4.26 & 81.7 & 4.30 & & \\
\hline & & 70 & 2.13 & 82.3 & 2.15 & & \\
\hline & & 52 & 10.3 & 71.9 & 10.8 & & \\
\hline & & 58 & 5.37 & 68.4 & 5.78 & & \\
\hline & Orioinal & 64 & 3.13 & 64.6 & 3.47 & $>1000$ & \\
\hline & & 70 & 1.99 & 60.7 & 2.28 & & \\
\hline & & 76 & 1.33 & 57 & 1.59 & & \\
\hline B-9- $\gamma-\mathrm{LDPE}_{\mathrm{R}}$ & & 82 & 0.881 & 53.4 & 1.10 & & PG 76-Y \\
\hline & & 52 & 51.4 & 69.1 & 55 & & \\
\hline & & 58 & 25 & 70.9 & 26.4 & & \\
\hline & Aged & 64 & 13 & 71.7 & 13.7 & $\geq 2200$ & \\
\hline & & 70 & 5 & 70.3 & 5.31 & & \\
\hline & & 76 & 2.89 & 68.2 & 3.11 & & \\
\hline & & 82 & 1.78 & 65.2 & 1.96 & & \\
\hline
\end{tabular}




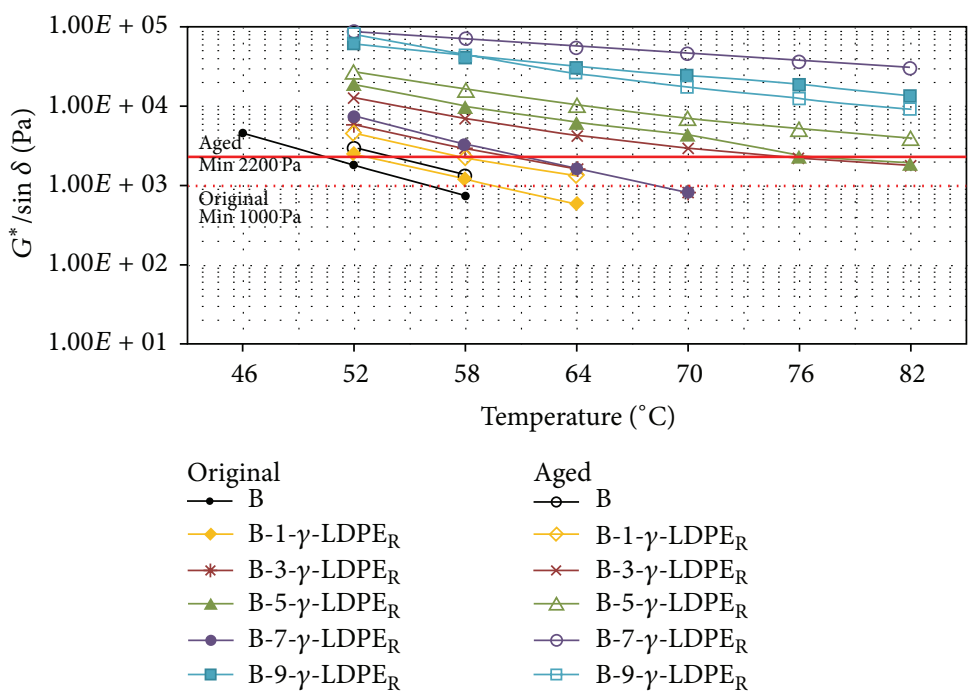

FIGURE 4: Rutting parameter of binders.

TABLE 5: Creep stiffness and $m$-value of the binders at a loading time of $60 \mathrm{~s}$ and different temperatures.

\begin{tabular}{|c|c|c|c|c|c|c|c|}
\hline \multirow{2}{*}{ Binder types } & \multicolumn{3}{|c|}{ Creep stiffness (MPa) } & \multicolumn{3}{|c|}{$m$-value } & \multirow{2}{*}{ Performance grading (PG) } \\
\hline & $-16^{\circ} \mathrm{C}$ & $-22^{\circ} \mathrm{C}$ & $-28^{\circ} \mathrm{C}$ & $-16^{\circ} \mathrm{C}$ & $-22^{\circ} \mathrm{C}$ & $-28^{\circ} \mathrm{C}$ & \\
\hline B & 42.13 & 99.50 & 199.05 & 0.479 & 0.432 & 0.309 & PG Y-28 \\
\hline B-1- $\gamma-\mathrm{LDPE}_{\mathrm{R}}$ & 40.71 & 139.69 & 219.12 & 0.381 & 0.343 & 0.281 & PG Y-22 \\
\hline B-3- $\gamma-\mathrm{LDPE}_{\mathrm{R}}$ & 67.61 & 146.12 & 228.33 & 0.325 & 0.318 & 0.274 & PG Y-22 \\
\hline B-5- $\gamma-\mathrm{LDPE}_{\mathrm{R}}$ & 66.93 & 156.68 & 248.98 & 0.324 & 0.301 & 0.285 & PG Y-22 \\
\hline B-7- $\gamma-\mathrm{LDPE}_{\mathrm{R}}$ & 78.77 & 176.58 & - & 0.311 & 0.267 & - & PG Y-16 \\
\hline B-9- $\gamma-L_{D P E}$ & 79.39 & 143.8 & - & 0.310 & 0.263 & - & PG Y-16 \\
\hline
\end{tabular}

$64-\mathrm{Y}$ and 76-Y from 52-Y, when content of the modifier is 5 and $9 \%$, respectively.

3.6. Bending Beam Rheometer Test. In order to study the influence of polymer additives on the low-temperature creep responses of bitumen, the bending beam rheometer test was employed at different loading times of $8,15,30,60,120$, and $240 \mathrm{~s}$ and temperatures of $-16^{\circ} \mathrm{C},-22^{\circ} \mathrm{C}$, and $-28^{\circ} \mathrm{C}$. Table 5 contains of compares creep stiffness and $m$-values obtained at three temperatures and at a loading time of $60 \mathrm{~s}$. The creep stiffness values and $m$-values of the base and $\gamma$-LDPE $E_{R}$ modified bitumens are also graphed in Figures 5 and 6 . As can be seen, creep stiffness of binders increases with increasing polymer modifier content. It can be said that this result was expected, as conventional and rotational viscosity test results indicate the effect stiffening of $\gamma$-LDPE $E_{\mathrm{R}}$ modification. Although it is known that binders with higher creep stiffness are not convenient for cold regions, as we can see from the results, the creep stiffness values of binders obtained do not exceed Superpave specifications (i.e., $300 \mathrm{MPa}$ ) at any test temperatures. As to $m$-value, there is a trend to exceed limitations with increasing polymer modifier content. Consequently, binders of B-7- $\gamma-\mathrm{LDPE}_{\mathrm{R}}$ and B-9- $\gamma-\mathrm{LDPE}_{\mathrm{R}}$ are failed at $-22^{\circ} \mathrm{C}$ to remain within specifications (i.e., 0.3) whereas the rest of the binders step up to next testing temperature. However, any of the binders were not able to provide $m$-value specification at $-28^{\circ} \mathrm{C}$ excepting base bitumen. Since creep stiffness is within the limitations, $m$ values determine the low-temperature performance grade of binders. Hence, there is a slightly decreasing trend in low-temperature performance grades as polymer modifier content increases. As can be seen from Table 5, it steps down to -22 and -16 from $-28^{\circ} \mathrm{C}$, as polymer modified content is increased to $1 \%$ and $7 \%$, respectively.

3.7. The Effect of $\gamma-L D P E_{\mathrm{R}}$ on Performance of Modified Bitumen. As it was discussed above, $\gamma-\mathrm{LDPE}_{\mathrm{R}}$ has positive the effect on high temperature performance grades, while it decreases slightly low temperature performance grades. Thus, in order to clarify the total effects of $\gamma$-LDPE $E_{R}$ on the performance and to recommend for optimum usage of $\gamma$ $\mathrm{LDPE}_{\mathrm{R}}$ in bitumen, Table 6 was prepared to show dependence of the modifier content on failure temperatures of binders for DSR and BBR test. Table 6 also contains the PG of the binders.

The results indicate that, the improvement at high temperatures can be seen clearly at even low polymer modification. For instance, B-1- $\gamma-\mathrm{LDPE}_{\mathrm{R}}$, which is able to be used in regions with a wider temperature range, as improvement of the binder, is $4.53^{\circ} \mathrm{C}$. As content of polymer modifier increases, the improvement also continues to increase. 
TABLE 6: The effect of $\gamma$-LDPE $E_{R}$ on high and low service temperatures and on performance grade (PG).

\begin{tabular}{|c|c|c|c|c|c|c|}
\hline Binder types & $\begin{array}{l}\text { Fails at } \\
\text { HT }\left({ }^{\circ} \mathrm{C}\right)\end{array}$ & $\begin{array}{l}\text { Fails at } \\
\text { LT }\left({ }^{\circ} \mathrm{C}\right)\end{array}$ & $\begin{array}{c}\mathrm{HT}\left({ }^{\circ} \mathrm{C}\right) \\
\text { improvement }\end{array}$ & $\begin{array}{c}\mathrm{LT}\left({ }^{\circ} \mathrm{C}\right) \\
\text { decrement }\end{array}$ & Improvement/decrement & Performance grading (PG) \\
\hline B & 54.3 & -28.78 & - & - & - & PG 52-28 \\
\hline B-1- $\gamma-\mathrm{LDPE}_{\mathrm{R}}$ & 61 & -26.61 & 6.7 & 2.17 & 4.53 & PG 58-22 \\
\hline B-3- $\gamma-\mathrm{LDPE}_{\mathrm{R}}$ & 63.5 & -24.45 & 9.2 & 4.33 & 4.87 & PG 58-22 \\
\hline B-5- $\gamma-\mathrm{LDPE}_{\mathrm{R}}$ & 66.9 & -22 & 12.6 & 6.78 & 5.82 & PG 64-22 \\
\hline B-7- $\gamma-\mathrm{LDPE}_{\mathrm{R}}$ & 68.6 & -20.5 & 14.3 & 8.28 & 6.02 & PG 64-16 \\
\hline B-9- $\gamma-\mathrm{LDPE}_{\mathrm{R}}$ & 80.5 & -17.95 & 26.2 & 10.83 & 15.37 & PG 76-16 \\
\hline
\end{tabular}

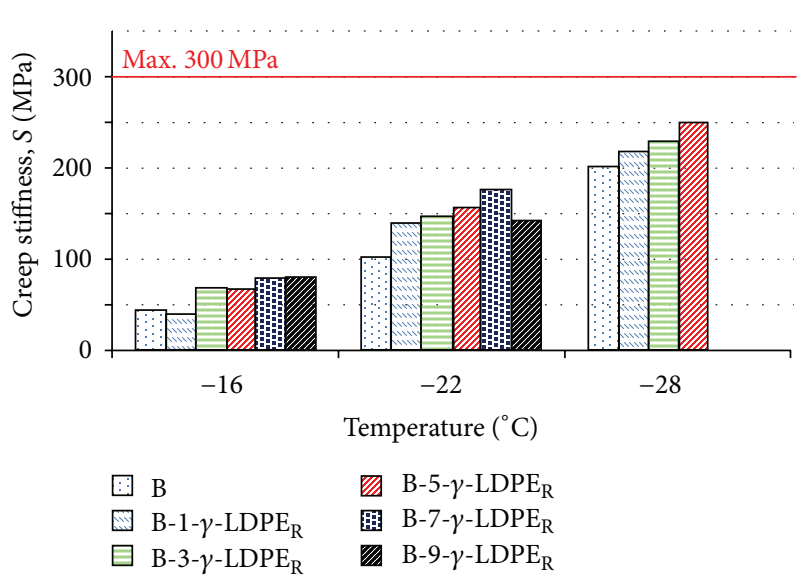

Figure 5: Creep stiffness values of the base and $\gamma$-LDPE $E_{R}$ modified bitumens.

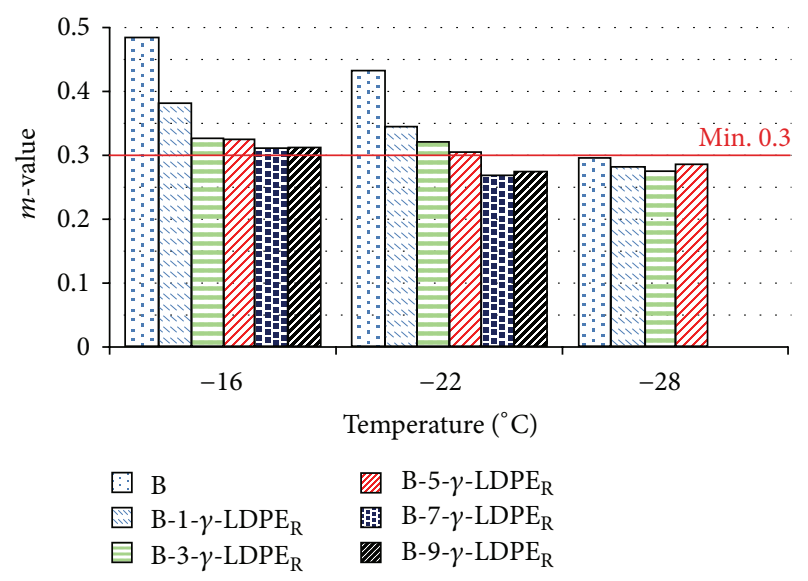

FIGURE 6: $m$-values of the base and $\gamma$-LDPE $\mathrm{R}_{\mathrm{R}}$ modified bitumens.

Thereby, temperature improvement of B-3- $\gamma-\mathrm{LDPE}_{\mathrm{R}}$ and B$5-\gamma-\mathrm{LDPE}_{\mathrm{R}}$ binders rises up to 4.87 and $5.82^{\circ} \mathrm{C}$, respectively. B-9- $\gamma-\mathrm{LDPE}_{\mathrm{R}}$ has the largest improvement with $15.37^{\circ} \mathrm{C}$. However, although failure temperatures are more precise than PG classifications, it is necessary that analyzing the effect of the polymer modifier by using both the failure temperatures and PG.

The PG of the base bitumen was found as PG 52-28, whereas $\mathrm{B}-1-\gamma-\mathrm{LDPE}_{\mathrm{R}}$ was a binder of PG 58-22. It can be understood that there is no improvement since hightemperature performance grade steps up to one level (52 to 58) while the decreasing in the low-temperature $P G$ is the same $(-28$ to -22$)$. However, in fact, as can be seen above there is an improvement in terms of failure temperatures.

B-3- $\gamma-\mathrm{LDPE}_{\mathrm{R}}$ has the same PG (58-22) with B-1- $\gamma$ $\mathrm{LDPE}_{\mathrm{R}}$, whereas B-5- $\gamma-\mathrm{LDPE}_{\mathrm{R}}$ has PG 64-22, which indicates there is an improvement in terms of both failure temperatures and PG. As for B-7- $\gamma$ - $\mathrm{LDPE}_{\mathrm{R}}$, low-temperature performance grading steps down to two level compared with base bitumen $(-16)$, thereby B-7- $\gamma$-LDPE $\mathrm{R}_{\mathrm{R}}$ has a poorer PG than $\mathrm{B}-5-\gamma-\mathrm{LDPE}_{\mathrm{R}}$. The B-9- $\gamma-\mathrm{LDPE}_{\mathrm{R}}$ has the biggest PG (76-16) along all the binders due to vast high-temperature improvement. It might be interpret as a benefit; however, this stiffening effect causes some problems in application while binder is being mixed and compacted. Nevertheless, it is undesirable due to high energy consumptions, as discussed in $\mathrm{RV}$ results.

Consequently, in spite of gradual increasing in temperature improvement as polymer content increases, as can be seen B-7- $\gamma$-LDPE $E_{R}$ and B-9- $\gamma$-LDPE $E_{R}$ have a lower temperature grade of -16 that also indicates that there must be a limitation to the usage of $\gamma-\mathrm{LDPE}_{\mathrm{R}}$. According to the rheological test (DSR and BBR), and considering RV results it can be suggested that the usage of $\gamma-\mathrm{LDPE}_{\mathrm{R}}$ polymers as modifier in bitumen with content of $5 \%$ as $\mathrm{B}-5-\gamma-\mathrm{LDPE}_{\mathrm{R}}$ has the most stable results due to the previously mentioned reasons.

\section{Conclusion}

$\gamma$-LDPE $E_{\mathrm{R}}$ modified bitumen has been investigated by means of conventional, chemical, and mechanical tests. It was found that the rheological properties of bitumen are enhanced with $\gamma$-LDPE $\mathrm{R}_{\mathrm{R}}$ polymer modification as identified by testing program. The surface images of the binders obtained with fluorescence microscopy revealed formation of multiphase system with bitumen continuous phase, $\gamma$-LDPE $\mathrm{R}_{\mathrm{R}}$ dispersed phase, and mixed phase (interfacial layer), which is a sign of the presence of chemical bonding between bitumen and gamma-irradiated polymer particles.

FTIR spectroscopy confirmed the appearance of reactive $\left(>\mathrm{C}=\mathrm{C}<\right.$ ) bonds in $\gamma-\mathrm{LDPE}_{\mathrm{R}}$ macromolecules after gamma irradiation of the $\mathrm{LDPE}_{\mathrm{R}}$. Conventional tests, such as penetration and softening point, indicate a significant increase in stiffness of the bitumen with increasing amount of the $\gamma$ $\mathrm{LDPE}_{\mathrm{R}}$ modifier. 
After short-term ageing by means of RTFOT, all the modified binders are within the Superpave limitations. Furthermore, $\gamma-\mathrm{LDPE}_{\mathrm{R}}$ polymer has a positive effect on bitumen ageing. In addition to the observed stiffening effect of $\gamma$ $\mathrm{LDPE}_{\mathrm{R}}$ on bitumen, RV test results also suggest that using $\gamma$ $\mathrm{LDPE}_{\mathrm{R}}$ as modifier more than $5 \%$ in bitumen can cause some mixing and compacting problems in applications.

The results obtained from the DSR tests show that $\gamma$ $\mathrm{LDPE}_{\mathrm{R}}$ modifier provides an increased complex shear modulus $\left(\mathrm{G}^{*}\right)$ values and rutting parameters $\left(\mathrm{G}^{*} / \sin \delta\right)$ and decreased phase angle $(\delta)$ values which means the $\gamma$-LDPE modified binders are more resistant against rutting compared to the base bitumen. This improvement also affects the PG of the binders that increases gradually with increasing modifier content. However, there must be a limitation for the usage of the $\gamma$-LDPE $\mathrm{R}_{\mathrm{R}}$ polymer due to BBR results that indicate an increasing creep stiffness and decreasing $m$-value as polymer content increases.

Consequently, in this paper, with taking into account the rheological tests and RV results, it was suggested that the optimum usage of $\gamma$-LDPE $E_{R}$ is $5 \%$ by weight of bitumen.

\section{Acknowledgments}

This work was carried out in the framework of the joint international Project no 110M400 of Ege University(Izmir, Turkey) and Institute of Macromolecular Chemistry of the National Academy of Sciences of Ukraine (NASU, Kyiv, Ukraine) under the agreement between TUBITAK (Turkey) and NASU (Ukraine).

\section{References}

[1] D. R. Gershkoff, J. Carswell, and J. C. Nicholls, Rheological Properties of Polymer-Modified Binders for Use in Rolled Asphalt Wearing Course, Transport Research Laboratory, Crowthorne, UK, 1997.

[2] U. Isacsson, "Laboratory investigation of polymer modified bitumens," Journal of the Association of Asphalt Paving Technology, vol. 68, pp. 35-63, 1999.

[3] G. D. Airey, "Rheological evaluation of ethylene vinyl acetate polymer modified bitumens," Construction and Building Materials, vol. 16, no. 8, pp. 473-487, 2002.

[4] A. Pérez-Lepe, F. J. Martínez-Boza, C. Gallegos, O. González, M. E. Muñoz, and A. Santamaría, "Influence of the processing conditions on the rheological behaviour of polymer-modified bitumen," Fuel, vol. 82, no. 11, pp. 1339-1348, 2003.

[5] M. García-Morales, P. Partal, F. J. Navarro, F. Martínez-Boza, M. R. Mackley, and C. Gallegos, "The rheology of recycled EVA/ LDPE modified bitumen," Rheologica Acta, vol. 43, no. 5, pp. 482-490, 2004.

[6] G. Polacco, S. Berlincioni, D. Biondi, J. Stastna, and L. Zanzotto, "Asphalt modification with different polyethylene-based polymers," European Polymer Journal, vol. 41, no. 12, pp. 2831-2844, 2005.

[7] N. Z. Habib, I. Kamaruddin, M. Napiah, and I. M. Tan, "Rheological properties of polyethylene and polypropylene modified bitumen," International Journal Civil and Environmental Engineering, vol. 3, pp. 96-100, 2011.
[8] C. F. Ouyang, Q. Gao, Y. T. Shi, and X. Q. Shan, "Compatibilizer in waste tire powder and low-density polyethylene blends and the blends modified asphalt," Journal of Applied Polymer Science, vol. 123, no. 1, pp. 485-492, 2012.

[9] M. García-Morales, P. Partal, F. J. Navarro, and C. Gallegos, "Effect of waste polymer addition on the rheology of modified bitumen," Fuel, vol. 85, no. 7-8, pp. 936-943, 2006.

[10] Z. Z. Ismail and E. A. AL-Hashmi, "Use of waste plastic in concrete mixture as aggregate replacement," Waste Management, vol. 28, no. 11, pp. 2041-2047, 2008.

[11] F. J. Navarro, P. Partal, M. García-Morales et al., "Bitumen modification with reactive and non-reactive (virgin and recycled) polymers: a comparative analysis," Journal of Industrial and Engineering Chemistry, vol. 15, no. 4, pp. 458-464, 2009.

[12] Y. H. Gad, M. M. Magida, and H. H. El-Nahas, "Effect of ionizing irradiation on the thermal blend of waste low density polyethylene/ethylene vinyl acetate/bitumen for some industrial applications," Journal of Industrial and Engineering Chemistry, vol. 16, no. 6, pp. 1019-1024, 2010.

[13] V. Wegan, Sampling for Microscopy-Test Procedure, Danish Road Institute, 1996.

[14] J. Read and D. Whiteoak, The Shell Bitumen Handbook, Shell Bitumen, Thomas Telford, London, UK, 5th edition, 2003.

[15] H. U. Bahia and D. A. Anderson, "Strategic highway research program binder rheological parameters: background and comparison with conventional properties," Transportation Research Record, no. 1488, pp. 32-39, 1995.

[16] J. P. Zaniewski and M. E. Pumphrey, Evaluation of Performance Graded Asphalt Binder Equipment and Testing Protocol, West Virginia University, 2004.

[17] G. D. Airey, "Rheological properties of styrene butadiene styrene polymer modified road bitumens," Fuel, vol. 82, no. 14, pp. 1709-1719, 2003.

[18] S. Liu, W. Cao, J. Fang, and S. Shang, "Variance analysis and performance evaluation of different crumb rubber modified (CRM) asphalt," Construction and Building Materials, vol. 23, no. 7, pp. 2701-2708, 2009.

[19] H. I. A. Wahhab, I. A. Al-Dubabe, I. M. Asi, and M. F. Ali, "Performance-based characterization of Arab asphalt," Building and Environment, vol. 33, no. 6, pp. 375-383, 1998. 

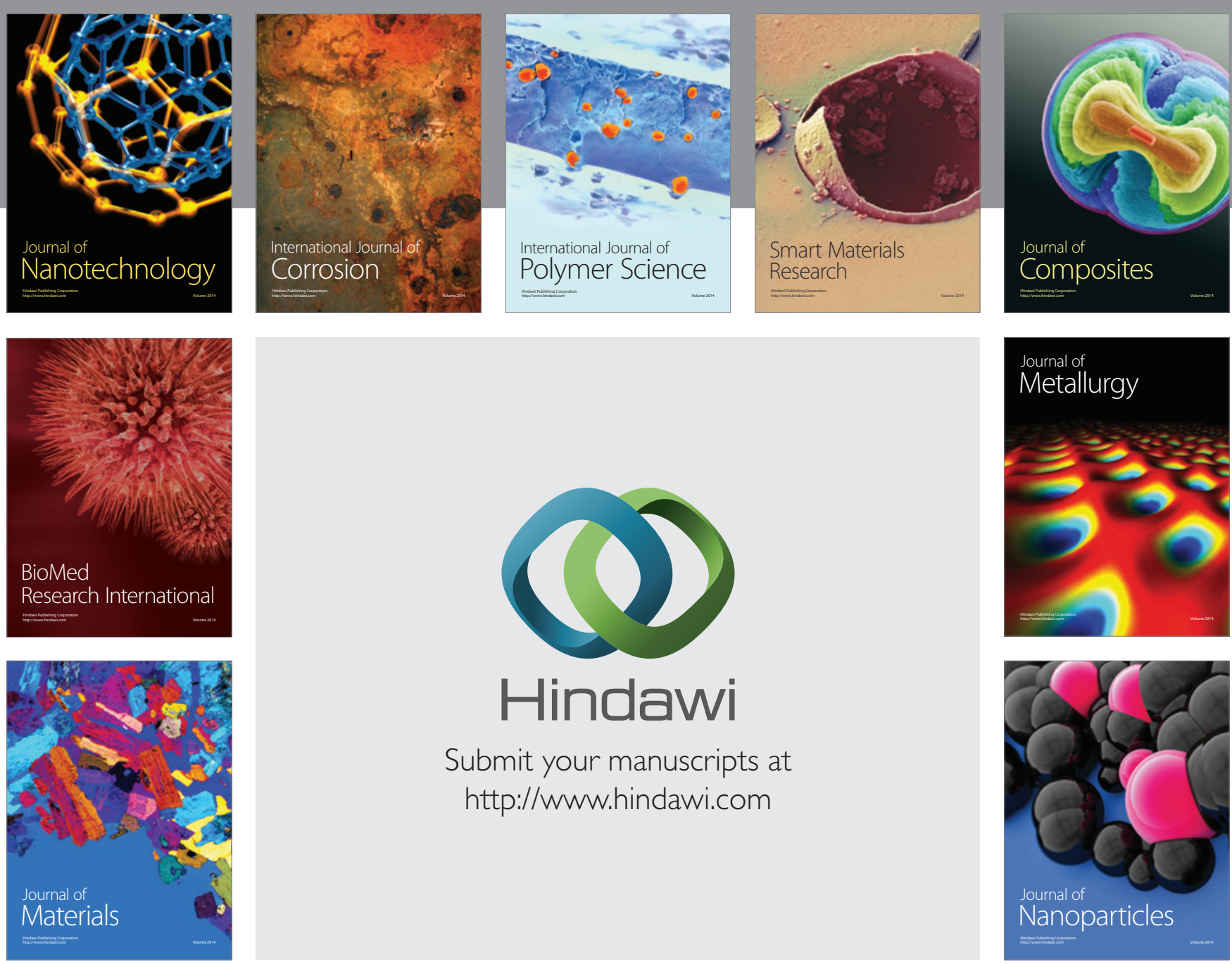

Submit your manuscripts at http://www.hindawi.com
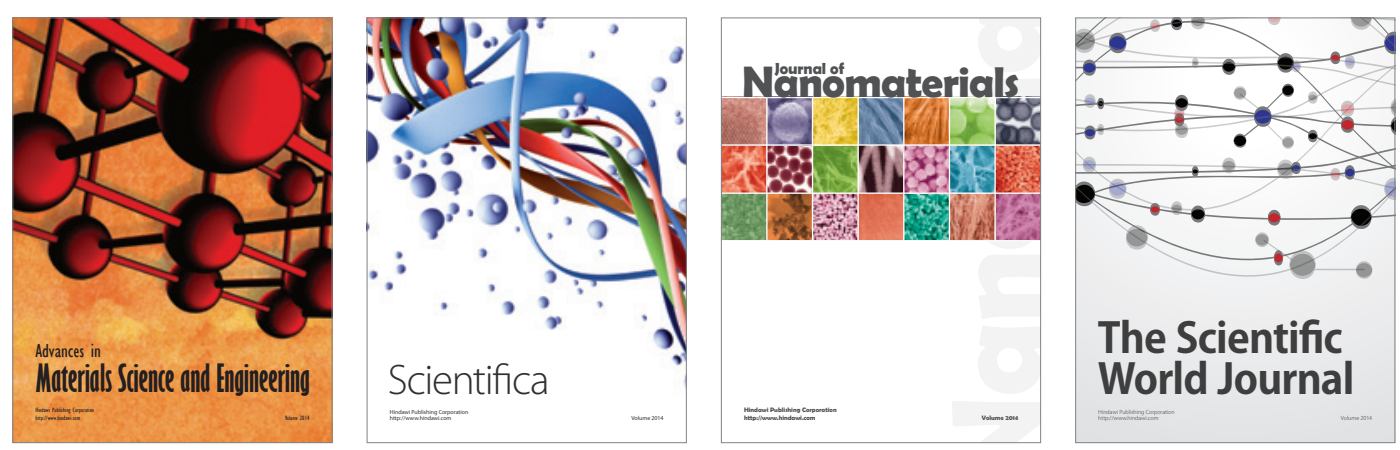

\section{The Scientific World Journal}
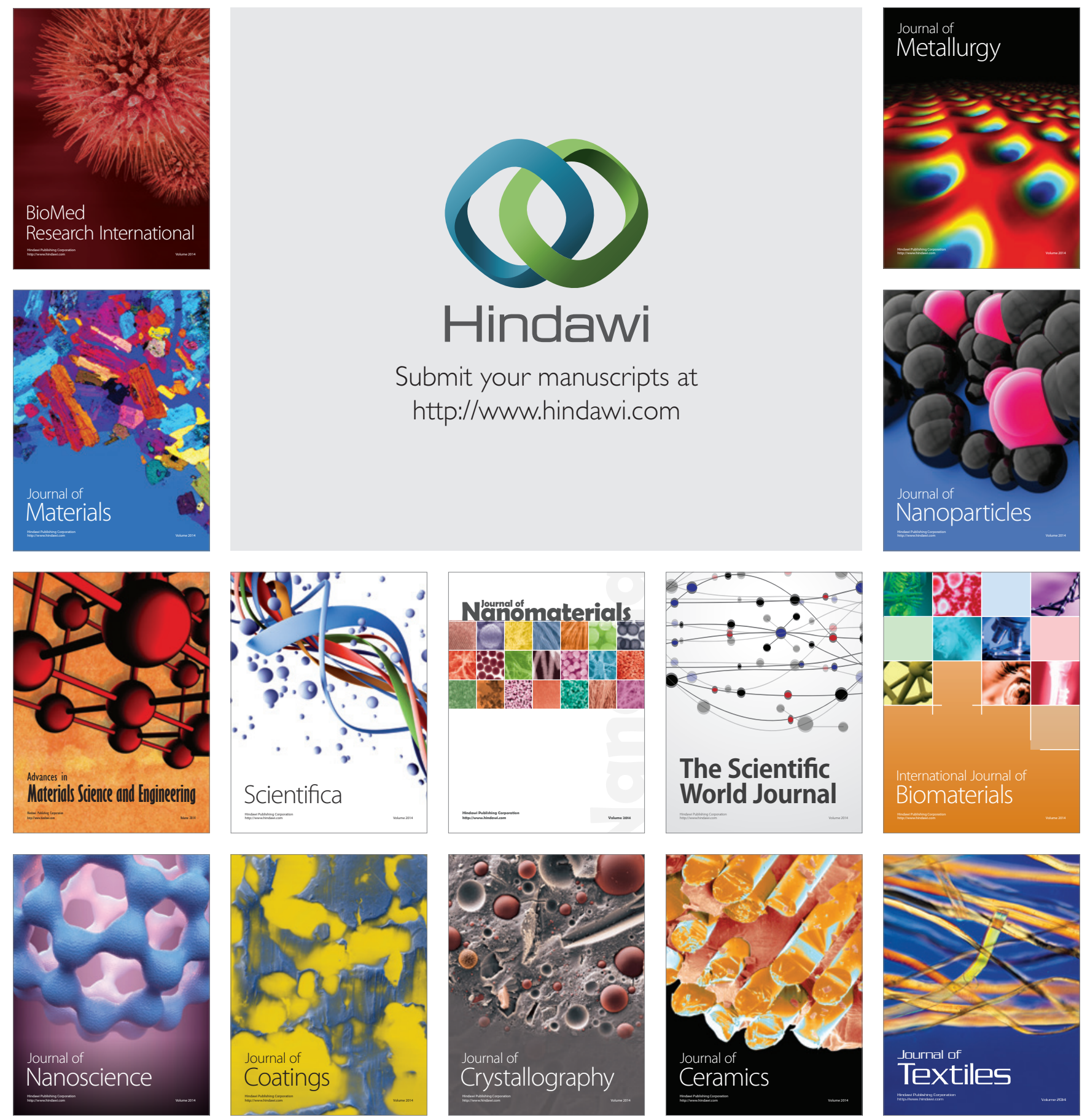